\title{
Annals of Case Reports and Images
}

\section{IMAGE}

\section{Aberrant Renal Vessels}

Shazia Waghoo, MS; Praveen Kammar, MS, MCh; Sanket Mehta, MS*

Department of Surgical Oncology, Kohinoor Hospital, Mumbai, India

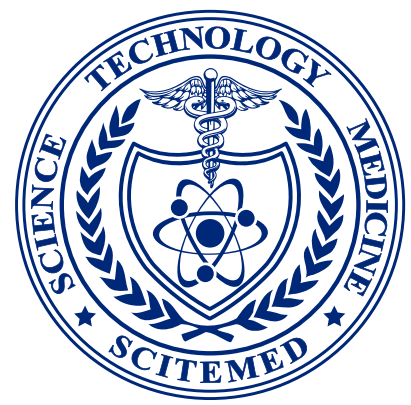

A 55-year-old postmenopausal lady presented with recurrent carcinoma of ovary. A computed tomography scan of the abdomen was performed after neoadjuvant chemotherapy, which showed retroaortic left renal vein and precaval right renal artery (Figure 1), along with the resolution of previous vaginal vault lesion. The intraoperative findings revealed a peritoneal carcinomatosis index of 3 , according to an incidental deposit found on the vaginal vault infiltrating into the rectum. During retroperitoneal lymph node dissection, as a part of the procedures in cytoreduction, aberrant renal vessels were identified. A complete clearance was done safeguarding the vessels as seen in the intraoperative image (Figure 2).
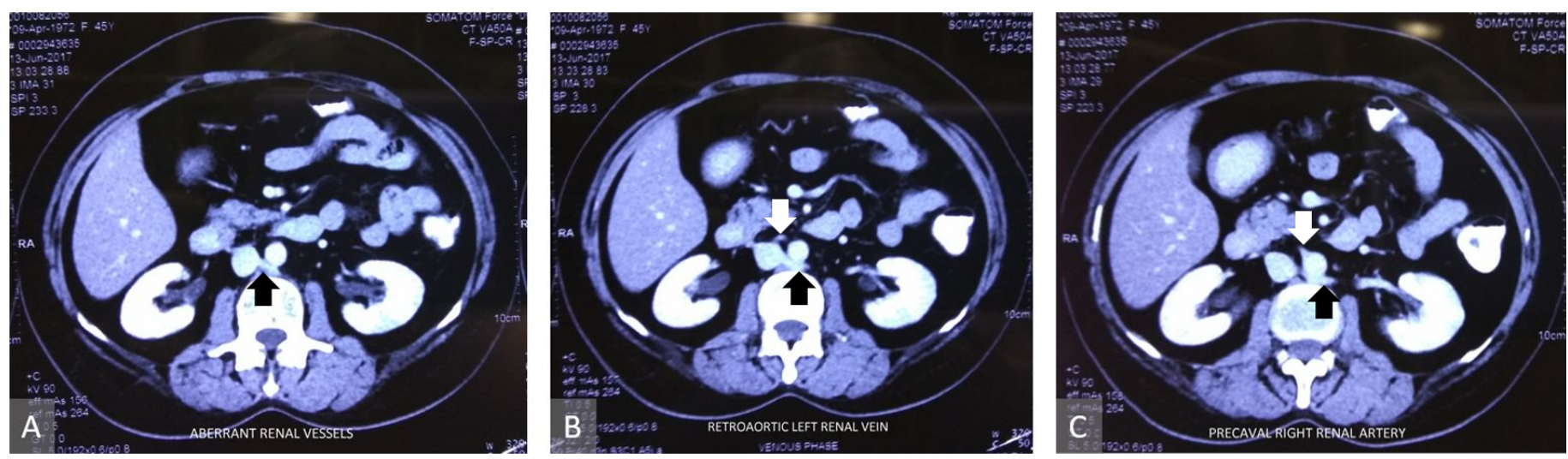

Figure 1. Contrast enhanced computed tomography images. Panel A, B, and C show the course of retroaortic left renal vein (black arrows). Precaval right renal artery is shown with the white arrow in Panel B and C.

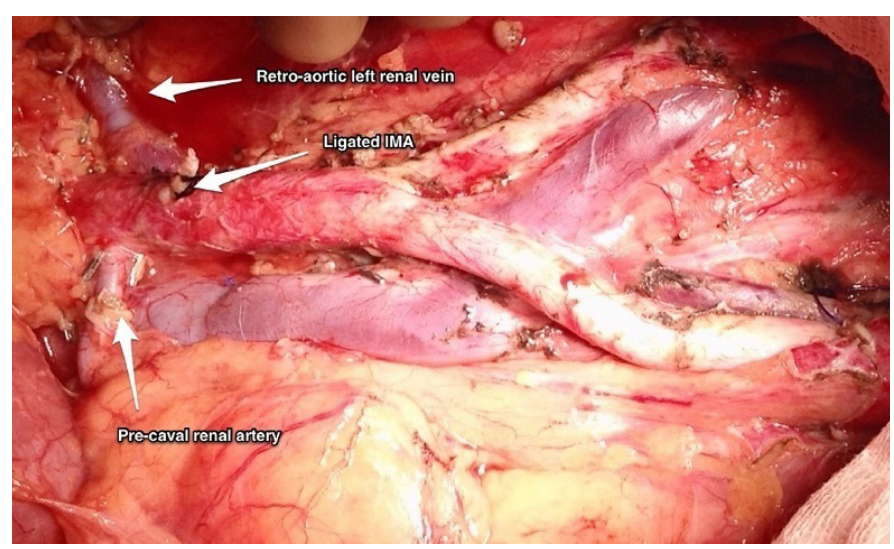

Figure 2. Aberrant renal vessels.

\section{Article Information}

*Correspondence: Sanket Mehta, MS

Department of Surgical Oncology, Kohinoor Hospital, Kirol Road, Ali Yavar Jung, Kurla West, Off LBS Road, Mumbai, Maharashtra 400070, India. Email: drmehtasanket@gmail.com

Received: Nov. 11, 2017; Accepted:Jun. 24, 2018; Published: Feb. 20, 2019

DOI: 10.24983/scitemed.acri.2019.00099

Copyright (c) 2019 The Author (s). This is an open-access article distributed under the terms of the Creative Commons Attribution 4.0 International License (CC-BY).

Funding: None

Conflict of Interest: None 